University of Nebraska - Lincoln

DigitalCommons@University of Nebraska - Lincoln

Faculty Papers and Publications in Animal

Science

Animal Science Department

1992

\title{
Genetic Variation Liver Mass, Body Mass, and Liver:Body Mass in \\ Mice
}

L. D. Jones

University of Nebraska-Lincoln

Merlyn K. Nielsen

University of Nebraska-Lincoln, mnielsen1@unl.edu

R. Britton

University of Nebraska-Lincoln

Follow this and additional works at: https://digitalcommons.unl.edu/animalscifacpub

Part of the Animal Sciences Commons

Jones, L. D.; Nielsen, Merlyn K.; and Britton, R., "Genetic Variation Liver Mass, Body Mass, and Liver:Body Mass in Mice" (1992). Faculty Papers and Publications in Animal Science. 484.

https://digitalcommons.unl.edu/animalscifacpub/484

This Article is brought to you for free and open access by the Animal Science Department at DigitalCommons@University of Nebraska - Lincoln. It has been accepted for inclusion in Faculty Papers and Publications in Animal Science by an authorized administrator of DigitalCommons@University of Nebraska - Lincoln. 


\title{
Genetic Variation in Liver Mass, Body Mass, and Liver:Body Mass in Mice ${ }^{1,2}$
}

\author{
L. D. Jones, M. K. Nielsen', and R. A. Britton \\ Department of Animal Science, University of Nebraska, Lincoln 68583-0908
}

ABSTRACT: Genetic variation for liver mass (LM), body mass (BM), and liver:body mass (LM/ BM) was examined for outbred populations of laboratory mice. Liver mass and body mass data were collected on 170 pureline sires at 12 wk of age, representing four outbred stocks of laboratory mice; 523 of their male and female two-waycross progeny at 9 or $12 \mathrm{wk}$; and 214 four-way-cross offspring at 12,14, or $16 \mathrm{wk}$. Genetic differences for $\mathrm{LM}, \mathrm{BM}$, and $\mathrm{LM} / \mathrm{BM}$ were found among the base sire lines and between two-way crosses. Heritabilities and genetic correlations for LM, BM, LM/BM, and $L M / M B M(M B M=B M \cdot 75)$ were estimated using offspring-sire regression within and across characteristics. Estimates of heritabilities and genetic correlations were also derived from full-sib covariances in the two-way-cross generation. Heritability estimates pooled over all analyses were $.53, .54, .36$, and .40 for LM, BM, LM/BM, and LM/MBM, respectively. Body mass was highly genetically correlated (.87) with LM and lowly correlated with LM/BM. Previous research has indicated possible positive relationships between $\mathrm{LM} / \mathrm{BM}$ and maintenance energy requirements in mature, nonlactating, nonpregnant animals. A selection index was developed for increasing BM but restricting genetic change in LM to zero. Selection using this index would be $40 \%$ as efficient in increasing $\mathrm{BM}$ as selection on $\mathrm{BM}$ alone but may hold maintenance energy requirements at a stable level.

Key Words: Mice, Body Weight, Liver Weight, Genetic Variation, Maintenance Energy

\section{Introduction}

One of the important focuses of livestock research is improvement of the economic efficiency of livestock production. One method of improving efficiency is to decrease the amount of energy required by the animal for body maintenance and, if intake remained unchanged, to use the extra energy above maintenance for production. Because the internal organs, especially the liver and gastrointestinal tract, play key roles in body metabolism, evidence suggests that variation in organ mass reflects differences in maintenance energy requirements (Koong et al., 1985; Burrin et al., 1988; Webster, 1988).

\footnotetext{
${ }^{1}$ Published as Paper no. 8809, Journal Ser., Nebraska Agric. Res. Div., Univ. of Nebraska, Lincoln 68583-0908.

${ }^{2}$ Appreciation is expressed to Jeryl Hauptman for maintaining the animal population and laboratory.

${ }^{3}$ To whom correspondence should be addressed: A218 Animal Sciences.

Received January 23, 1982.

Accepted June 1, 1982.
}

Previous research has indicated that genetic variation exists for organ weights in laboratory animals that have been selected for increased BW or growth. Bünger et al. (1985) found that the absolute weights of hearts, livers, and kidneys were significantly higher in lines of mice selected for high BW, high protein content, or an index of BW and endurance fitness. Relative liver weights also increased in the selected lines. Comparing male mice from a line selected for rapid postweaning gain with a control line at the same age or degree of maturity, Eisen (1986) found that selected males weighed more and had larger organ (spleen, liver, heart, kidneys, small intestine, stomach, testes) masses at either similar ages or similar maturities. Using the Goodale giant strain $(\mathrm{G} / \mathrm{Gw})$ of mice produced by selection for increased BW at $60 \mathrm{~d}$ of age, Nash and Logsdon (1978) found that the liver and kidneys were relatively larger, nonproportional to the increase in body size relative to the control group. The increase in liver weight was associated with increased levels of liver glycogen.

The objective of this work was to measure genetic variation and covariation in laboratory 
Table 1. Distribution of observations by age and sex in pure lines and two-way and four-way crosses

\begin{tabular}{|c|c|c|c|c|c|c|}
\hline \multirow{2}{*}{$\begin{array}{l}\text { Line or } \\
\text { cross }^{\mathbf{a}}\end{array}$} & \multirow{2}{*}{$\begin{array}{l}\text { Female, } \\
\text { 9-wk }\end{array}$} & \multicolumn{4}{|c|}{ Male } & \multirow[b]{2}{*}{ Total } \\
\hline & & 8-wk & 12-wk & 14-wk & 16-wk & \\
\hline A & - & - & 38 & - & - & 38 \\
\hline B & - & - & 42 & - & - & 42 \\
\hline C & - & - & 44 & - & - & 44 \\
\hline D & - & - & $4 \theta$ & - & - & 46 \\
\hline Total & - & - & 170 & - & - & 170 \\
\hline$A \cdot B$ & 42 & 41 & 42 & - & - & 125 \\
\hline B. A & 35 & 40 & 38 & - & - & 114 \\
\hline C.D & 58 & 56 & 42 & - & - & 156 \\
\hline D.C & 43 & 44 & 41 & - & - & 128 \\
\hline Total & 178 & 181 & 164 & - & - & 523 \\
\hline $\mathrm{AB} \cdot \mathrm{CD}$ & - & - & 18 & 18 & 18 & 54 \\
\hline $\mathrm{BA} \cdot \mathrm{DC}$ & - & - & 18 & 18 & 18 & 54 \\
\hline $\mathrm{CD} \cdot \mathrm{AB}$ & - & - & 18 & 18 & 18 & 54 \\
\hline $\mathrm{DC} \cdot \mathrm{BA}$ & - & - & 18 & 18 & 18 & 54 \\
\hline Total & - & - & 72 & 72 & 72 & 216 \\
\hline
\end{tabular}
lines.

mice for liver mass (LM), body mass (BM), and liver:body (LM/BM) and liver:metabolic body mass (LM/MBM), with the latter two as indicators of possible genetic variation in energy requirement adjusted for body size.

\section{Materials and Methods}

Origin of Population and General Management. Mice representing four outbred stocks were obtained from Charles River (CR) and Harlan Sprague Dawley (HSD) laboratories in the fall of 1989 to develop a four-way-composite population. Original stocks were assigned line codes as follows: $A=H S D, N I H$ strain; $B=H S D, I C R$ strain; $C=C R, C F-1$ strain; and $D=C R, C F W(S w)$ strain. Approximately 40 nonsib males and females were acquired from each line at $3 \mathrm{wk}$ of age. Animals were paired at $\theta$ wk to produce two-waycross progeny $(A B, B A, C D$, and $D C$ crosses, see Table 1). Litters were standardized to eight pups at birth, with an ideal male to female ratio of $4: 4$. Two male and two female siblings were randomly selected at the time of weaning. Two-way-cross progeny were weaned at $3 \mathrm{wk}$ of age and mated at 8 wk to produce $F_{1}$, four-way-cross progeny $(A B C D$, $\mathrm{BADC}, \mathrm{CDAB}$, and $\mathrm{DCBA}$. The $\mathrm{F}_{1}$ progeny were weaned at 3 wk and randomly assigned to one of three replicates. Replicate 1 was mated at $8 \mathrm{wk}$ of age, Replicate 2 at $10 \mathrm{wk}$, and Replicate 3 at $12 \mathrm{wk}$ (see Figure 1 for a flow chart of the mating and animal measurement scheme).

All mice were allowed ad libitum access postweaning and during the breeding period to a diet of Wayne ${ }^{T M}$ Rodent Blox 8604 (24\% CP, $4 \%$ crude fat, $4.5 \%$ crude fiber). During lactation, dams and pups were given ad libitum access to a diet of Wayne $^{\mathrm{TM}}$ Mouse Breeder Blox $8626(20 \%$ CP, $10 \%$ crude fat, $2 \%$ crude fiber). Water was available on an ad libitum basis. All mice were housed under controlled conditions of $25^{\circ} \mathrm{C}$ and a $12 \mathrm{~h}: 12 \mathrm{~h}$ light: dark cycle.

Data Collection. Base population, pure-line sires were removed from mating cages at 12 wh of age and euthanatized by cervical dislocation. For each animal, BM was recorded and the liver was excised, rinsed, and blotted and its mass was recorded. For the two-way-cross progeny, one female and one male sibling from each litter were euthanatized at approximately the time of mating their sibs $(\theta \mathrm{wk})$ and data collected. The remaining male sibling was paired with a female and euthanatized after mating (12 wk). The $F_{1}$, four-waycross males were euthanatized after mating (12, 14 , or $16 \mathrm{wk}$ depending on replicate) and data collected at that time. The number of animals measured was 170,523 , and 214 for pure-line, twoway-cross, and four-way-cross generations, respectively.

Analysis. The data were analyzed using the GLM procedure of SAS (1985) and the LSMLMW program by Harvey (1987). Orthogonal contrasts were used in comparing line and cross differences. Because the two-way crosses were formed by reciprocal crosses of lines $A$ and $B$ and of lines $C$ and $D$, contrasts of the pure-line data were as follows: $A, B$ vs $C, D ; A$ vs $B$; and $C$ vs $D$. Likewise, in the two-way crosses, the contrasts were as follows: $A B, B A$ vs $C D, D C ; A B$ vs $B A$; and $C D$ vs $D C$. In the four-way-cross data, contrasts were as 
follows: $A B C D, B A D C$ vs $C D A B, D C B A ; A B C D$ vs $B A D C$; and $C D A B$ vs $D C B A$. Contrasts of the pureline data would test differences of combined direct effects, maternal effects, and possible cytoplasmic and(or) grandmaternal effects of the lines. Comparisons of reciprocal two-way crosses would test differences of combined maternal effects and possible cytoplasmic and(or) grandmaternal effects, and the latter two comparisons of the fourway crosses would test for possible cytoplasmic and(or) grandmaternal differences of the foundation lines.

Heritability and genetic correlation estimates for $\mathrm{LM}, \mathrm{BM}, \mathrm{LM} / \mathrm{BM}$, and $\mathrm{LM} / \mathrm{MBM}(\mathrm{MBM}=$ $B{ }^{75}$ ) were generated using offspring-sire regression within characteristics and across characteristics. Regressions of two-way-cross progeny on pure-line sires were as follows: 9 -wk daughters on 12-wk sires (YF-S); $\theta$-wk sons on 12-wk sires (YM-S); 12-wk sons on 12-wk sires (MM-S); and a pooled regression using all offspring. Regression coefficients for the YF.S regressions were corrected for differences in variance between the male and female populations according to the formula of

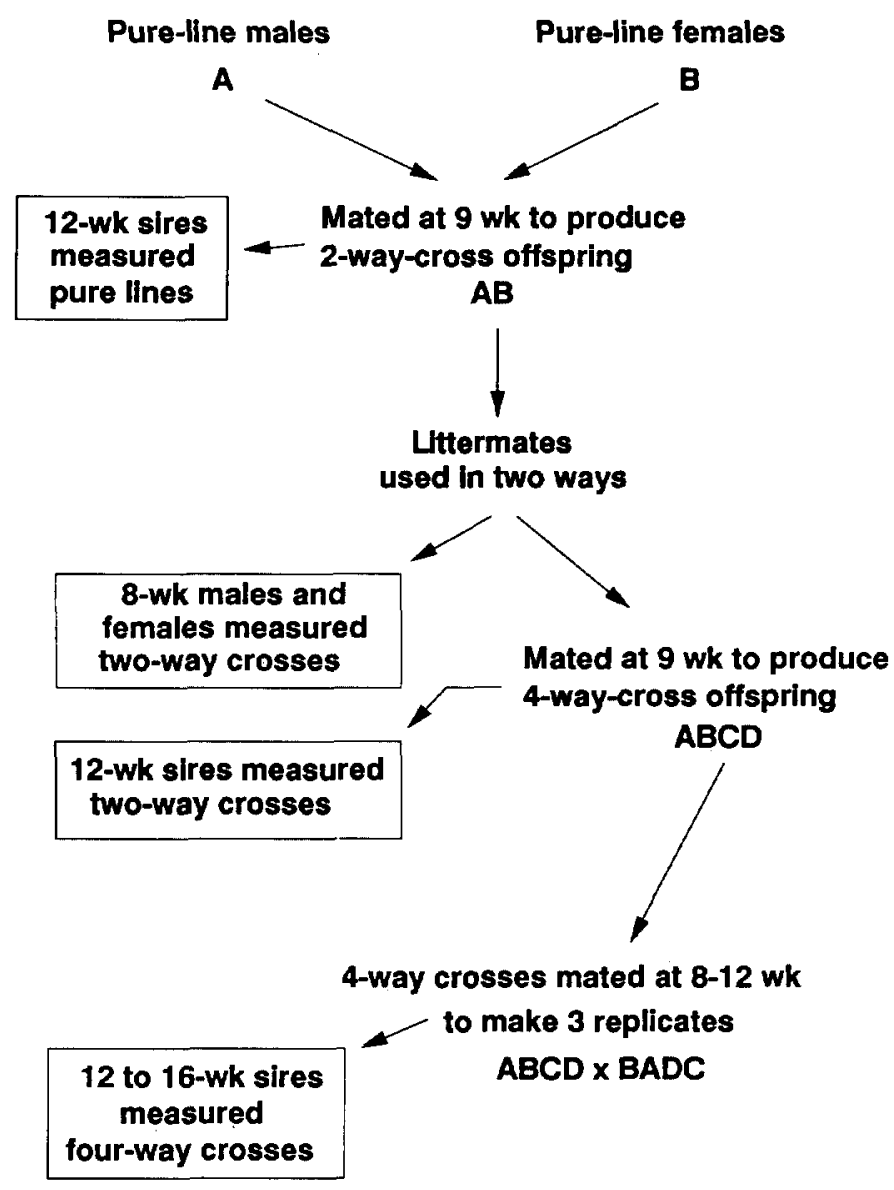

Figure 1. Flow chart of mating scheme and animals measured: pure lines, two-way crosses, and four-way crosses.
Falconer (1989). Models for two-way-cross progeny included the effects of sire line and sex-age class with the regression on the pure-line sire. The model for four-way-cross progeny included the effects of sire line and replicate with the regression on the two-way-cross sire.

Heritability and genetic correlation estimates were also derived in the two-way-cross generation using full-sib covariances. Covariances were calculated between 9 -wk brother and sister pairs (YMYF), 12-wk brother and 9-wk sister pairs (MM-YF), and 12-wk and 9-wk brother pairs (MM-YM), as well as between all sibs. The models included the effects of sire line and sex-age classes. Phenotypic correlations between characteristics were calculated from a pooled data analysis across generations, accounting for line or cross, sex, age, and replicate groups.

\section{Results and Discussion}

\section{Line and Cross Means}

Least squares means for LM, BM, and LM/BM are shown in Table 2 by line and cross. Pooled phenotypic standard deviations for $\mathrm{LM}$ and $\mathrm{BM}$ were .24 and 2.9 , with $C V$ of 12 and $9 \%$, respectively. Pure lines $A$ and $B$ differed from lines $C$ and $\mathrm{D}$ for $\mathrm{BM}(P<.01), \mathrm{LM} / \mathrm{BM}(P<.002)$, and $\mathrm{LM} /$ MBM $(P<.05)$. Contrasts of $A$ vs $B$ and $C$ vs $D$ were significant $(P<.001)$ for $L M, B M, L M / B M$, and $\mathrm{LM} / \mathrm{MBM}$.

Table 2. Least squares means for liver, body, and liver:body mass by line or cross

\begin{tabular}{|c|c|c|c|}
\hline $\begin{array}{l}\text { Line or } \\
\text { cross }^{\text {a }}\end{array}$ & Liver, $\mathbf{g}$ & Body, $\mathrm{g}$ & Liver:body \\
\hline \multicolumn{4}{|c|}{ Base generation pure-line sires } \\
\hline A & 1.60 & 32.1 & .050 \\
\hline $\mathbf{B}$ & 2.16 & $36 . \theta$ & .059 \\
\hline C & 2.08 & 35.3 & .058 \\
\hline $\mathrm{D}$ & 1.68 & 31.4 & .054 \\
\hline \multicolumn{4}{|c|}{ - First generation two-way-cross progeny } \\
\hline$A \cdot B$ & 1.88 & 31.5 & .059 \\
\hline B. A & 2.01 & 31.6 & .064 \\
\hline $\mathrm{C} \cdot \mathrm{D}$ & 1.89 & 30.4 & .062 \\
\hline $\mathrm{D} \cdot \mathrm{C}$ & 1.80 & 31.1 & .058 \\
\hline \multicolumn{4}{|c|}{ Second generation four-way-cross progeny } \\
\hline$A B \cdot C D$ & 2.08 & 35.1 & .058 \\
\hline $\mathrm{BA} \cdot \mathrm{DC}$ & 2.04 & 35.2 & .058 \\
\hline $\mathrm{CD} \cdot \mathrm{AB}$ & 2.02 & 35.1 & .057 \\
\hline $\mathrm{DC} \cdot \mathrm{BA}$ & 2.06 & 38.0 & .057 \\
\hline
\end{tabular}

aSee Table 1 for line and cross codes and for sex and age classes in pure-line, two-way-cross, and four-way-cross individuals. 
Table 3. Heritability estimates from offspring-sire regressions

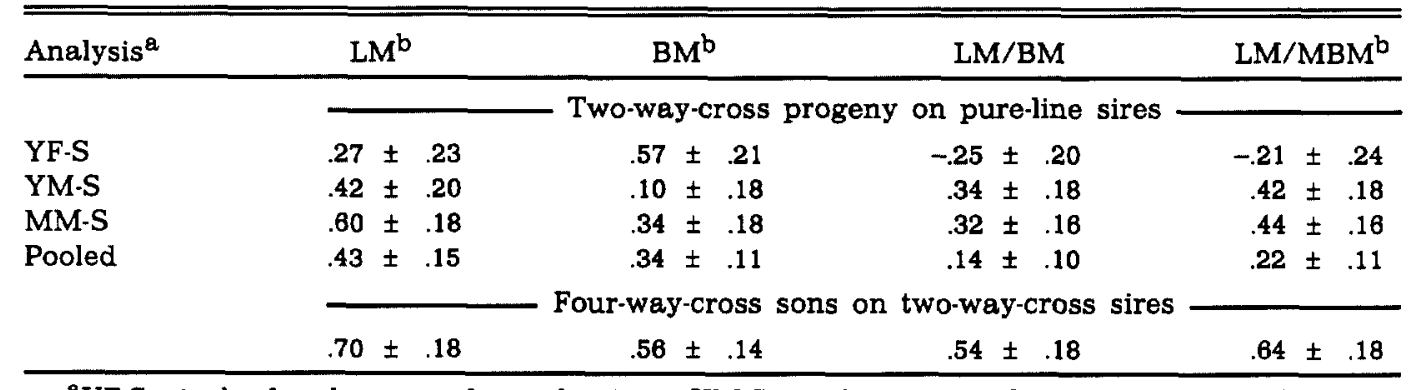

aYF-S: 9-wk daughters and 12-wk sires, YM-S: 8-wk sons and 12-wk sires, and MM-S: 12-wk sons and 12-wk sires.

$\mathrm{b}_{\mathrm{LM}}=$ liver mass, $\mathrm{BM}=$ body mass, and $\mathrm{MBM}=$ metabolic body mass.

Analysis of two-way-cross progeny exhibited highly significant differences $(P<.001)$ for all traits when $\mathrm{AB}$ and $\mathrm{BA}$ crosses were compared to $C D$ and $D C$ crosses. When $A B$ progeny were contrasted with BA progeny, highly significant differences were found for LM, LM/BM, and LM/ MBM $(P<.001)$. Comparison of CD vs DC crosses indicated highly significant differences $(P<.001)$ for LM, LM/BM, and LM/MBM; a significant $P<$ .05) difference was found for $B M$. Contrasts of $A B C D$ and $B A D C$ crosses vs $C D A B$ and DCBA crosses indicated a significant difference $(P<.05)$ for LM/BM; for all other contrasts of the four-waycross means were nonsignificant for all traits.

Nash and Logsdon (1978) reported differences between 8-wk $\mathrm{G} / \mathrm{Gw}$ (Goodale giant strain) and randomly bred males for LM, BM, and LM/BM (.074 for $G / G w$ and .055 for random bred). Eisen (1886) found significant differences for LM/BM between male mice selected for rapid postweaning growth and unselected control males compared at $37.5,62.5,75.0,87.5$, and $100 \%$ of mature BW. At $100 \%$ of mature BW, the proportions of LM relative to $\mathrm{BM}$ were .075 and .066 for selected and control males, respectively. Data from Marshall et al. (1957) demonstrated differences in BW and liver weight for obese-hyperglycemic la hereditary form of obesity) mice and nonobese controls. Calculations from the reported data indicated no difference in LM/BM for young adult mice (12 to $16 \mathrm{wk}$ ) between the obese and control samples. However, older (40 to $52 \mathrm{wk}$ ) control mice had a higher proportion of LM/BM than did their obese contem. poraries (.059 vs .046).

\section{Heritabilities and Genetic Variation}

Heritability estimates for all traits are listed by method of analysis in Tables 3 and 4 . Genetic and phenotypic correlations are shown in Tables 5, 6, and 7 . It should be noted that heritability estimates resulting from full-sib analysis of covariance may include possible nonadditive (dominance, maternal, andlorl environmental) effects that may inflate the estimate. On the other hand, any of the full-sib or offspring-sire estimates using relatives with different ages may be biased downward unless the genetic correlation between measurements at these ages was 1 and they had equal genetic variances. A discussion by trait follows.

Body Mass. Heritability estimates for BM calculated from these data vary widely across analyses. A low estimate of .10 was found using the regression of young males on their sire, with a high estimate of .78 determined from the full-sib covariance between mated males and young males. Possible biases outlined above along with sampling error may explain these discrepancies. Pooled heritabilities were $.34, .70$, and .56 for

Table 4. Heritability estimates from full-sib analyses

\begin{tabular}{|c|c|c|c|c|c|}
\hline Analysis $^{a}$ & $\mathrm{LM}^{\mathrm{b}}$ & $\mathrm{BM}^{\mathrm{b}}$ & $\mathrm{LM} / \mathrm{BM}$ & \multicolumn{2}{|c|}{$\begin{array}{c}\mathrm{LM} / \\
\mathrm{MBM}^{\mathrm{b}}\end{array}$} \\
\hline YM-YF & $.35 \pm .14$ & $.73 \pm .13$ & $.44 \pm .14$ & $.28 \pm$ & .15 \\
\hline MM-YF & $.47 \pm .15$ & $.58 \pm .14$ & $.41 \pm .15$ & $.40 \pm$ & .15 \\
\hline $\mathrm{MM}-\mathrm{YM}$ & $.65 \pm .14$ & $.78 \pm .13$ & $.68 \pm .14$ & $.62 \pm$ & .14 \\
\hline All sibs & $.53 \pm .10$ & $.70 \pm .10$ & $.52 \pm .10$ & $.47 \pm$ & .10 \\
\hline
\end{tabular}

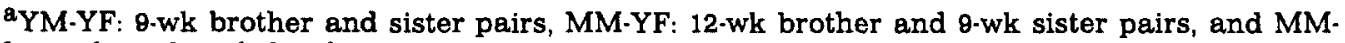
YM: 12 -wk and $\theta$-wk brother pairs.

${ }^{b} \mathrm{LM}=$ liver mass, $\mathrm{BM}=$ body mass, and $\mathrm{MBM}=$ metabolic body mass. 
Table 5. Genetic correlations between liver and body mass measures estimated by regression of two-way-cross offspring on pure-line sires and four-way-cross sons on two-way-cross sires ${ }^{a}$

\begin{tabular}{|c|c|c|c|c|}
\hline Item & $\mathrm{BM}^{\mathrm{b}}$ & $\mathbf{L M}^{\mathrm{b}}$ & LM/BM & $\mathrm{LM} / \mathrm{MBM}^{\mathrm{b}}$ \\
\hline BM & & $\begin{array}{r}.00 \\
(.04)\end{array}$ & $\begin{array}{r}.66 \\
(.18)\end{array}$ & $\begin{array}{r}.78 \\
(.11)\end{array}$ \\
\hline LM & $\begin{array}{c}.88 \\
(.04)\end{array}$ & & $\begin{array}{r}.94 \\
(.10)\end{array}$ & $\begin{array}{r}.97 \\
(.01)\end{array}$ \\
\hline LM/BM & $\begin{array}{r}.28 \\
(.18)\end{array}$ & $\begin{array}{r}.77 \\
(.08)\end{array}$ & & $\begin{array}{r}.99 \\
(.01)\end{array}$ \\
\hline LM/MBM & $\begin{array}{r}.81 \\
(.12)\end{array}$ & $\begin{array}{r}.81 \\
(.03)\end{array}$ & $\begin{array}{r}.96 \\
(.02)\end{array}$ & \\
\hline
\end{tabular}

\footnotetext{
${ }^{a}$ Genetic correlations using two-way-cross progeny and pure-line sires: upper right. Genetic correlations using four-way-cross sons and two-way cross sires: lower left. Standard error for estimates in parentheses.

${ }^{b_{L M}}=$ liver mass, $\mathrm{BM}=$ body mass, and $\mathrm{MBM}=$ metabolic body mass.
}

offspring-sire regression (cross-line progeny on base sires), full-sib analysis of covariance, and sonsire regression (four-way-cross sons on two-waycross sires), respectively. A realized heritability estimate from selection for increased 10-wk BM of .33 was reported by McCarthy and Doolittle (1877); an estimate from parent-offspring regression of .35 has also been reported for 10-wk BM (Sharp et al., 1984). For 12-wk BM, a realized heritability estimate of .41 was reported by Baker et al. (1991); Eisen and Prasetyo (1988) reported an estimate of .43 from parent-offspring regression analysis.

Liver Mass. Pooled heritability estimates for LM of $.43, .53$, and .70 indicate that LM is moderately to highly heritable. Heritability estimates for LM were lowest for analyses including females isee YF-S regression [Table 3], MM-YF full-sib analysis [Table 4]). Stronger relationships were found using the covariance between males, and especially between males of equal age, indicating that the genetic correlation between the measurements of the ages observed here was not 1 .

Liver Mass:Body Mass. Pooled heritability estimates for LM/BM were $.14, .52$, and .54 for offspring-sire (cross-line progeny on base sires) regression, full-sib analysis, and son-sire four-waycross sons on two-way-cross sires) regression, respectively. Estimates for LM/MBM tended to be slightly higher than those for LM/BM but followed the same trend. A negative coefficient occurred with the regression of young females on their sires. This may indicate a negative correlation for the expression of this trait between males and females; however, this seems highly unlikely, because the source of the negative coefficient can be traced to one of the four base lines.

Genetic and Phenotypic Correlations. Estimated genetic correlations calculated from offspring-sire regression for two-way and four-way crosses are shown in Table 5; genetic correlations calculated from full-sib covariance are shown in Table 6 . Pooled phenotypic correlations are shown in Table 7 . Both phenotypic and genetic correlations followed the same trend; LM was highly correlated with all other traits. Phenotypic correlation estimates were very consistent between analysis by full-sib covariance and pooled data regression. Estimates of the phenotypic correlation between LM and BM were slightly higher than an estimate of .72 reported by Eisen et al. (1978). Body mass

Table 6. Genetic correlations between liver and body mass measures estimated in full-sib analysis

\begin{tabular}{|c|c|c|c|c|}
\hline Item & $\mathrm{BM}^{\mathrm{a}}$ & $\mathrm{LM}^{\mathrm{a}}$ & $\mathrm{LM} / \mathrm{BM}$ & $\mathrm{LM} / \mathrm{MBM}^{\mathrm{\theta}}$ \\
\hline BM & & $\begin{array}{r}.81 \\
(.05)\end{array}$ & $\begin{array}{l}-.11 \\
(.15)\end{array}$ & $\begin{array}{r}.26 \\
(.14)\end{array}$ \\
\hline LM & & & $\begin{array}{r}.50 \\
(.11)\end{array}$ & $\begin{array}{r}.78 \\
(.08)\end{array}$ \\
\hline LM/BM & & & & $\begin{array}{r}.83 \\
(.02)\end{array}$ \\
\hline
\end{tabular}

$\mathrm{LM} / \mathrm{MBM}$

\footnotetext{
${ }^{a} \mathrm{LM}=$ liver mass, $\mathrm{BM}=$ body mass, and MBM = metabolic body mass. Standard error for
} estimates in parentheses. 
Table 7. Phenotypic correlations between liver and body mass measures

\begin{tabular}{lcccc}
\hline \hline Item & $\mathrm{BM}^{\mathrm{a}}$ & $\mathrm{LM}^{\mathrm{a}}$ & $\mathrm{LM} / \mathrm{BM}$ & $\mathrm{LM} / \mathrm{MBM}^{\mathrm{a}}$ \\
\hline $\mathrm{BM}$ & .80 & .11 & .38 \\
$\mathrm{LM}$ & & .70 & .86 \\
$\mathrm{LM} / \mathrm{BM}$ & & & & .96 \\
\hline
\end{tabular}

${ }^{a} \mathrm{LM}=$ liver mass, $\mathrm{BM}=$ body mass, and $\mathrm{MBM}=$ metabolic body mass.

was lowly (and sometimes negatively) correlated with both $\mathrm{LM} / \mathrm{BM}$ and $\mathrm{LM} / \mathrm{MBM}$.

Discussion. In domestic animals, energy metabolism of visceral organs, measured directly, accounted for 40 to $50 \%$ of total energy requirements (Smith and Baldwin, 1974; Webster, 1981; Burrin et al., 1988). Previous research has demonstrated that differences in maintenance energy requirements exist between breeds and strains of livestock species that differ in genetic potential for growth and(or) production (Ferrell and Jenkins, 1984; Montaño-Bermudez et al., 1990; Taylor and Murray, 1991). Additionally, it has been demonstrated that differences in plane of nutrition result in differences in visceral organ size and metabolic activity and(or) fasting heat production (Koong et al., 1982, 1985; Ferrell and Koong, 1986; Burrin et al., 1990).

Jenkins et al. (1986) suggested that larger relative LM were associated with higher potential for either body size or milk production. Research reported by DiCostanzo and associates (1890) found a positive correlation between daily $\mathrm{ME}_{\mathrm{m}}$ intake and liver weight and relative proportion of liver in the empty body for nonpregnant, nonlactating beef cows. This indicates a positive relationship between maintenance energy requirement and relative LM. Therefore, changes in energy required for maintenance should result in proportional changes in relative $L M$, and vice versa.

Examination of the linear contrasts reveals the possible importance of direct, maternal, and grandmaternal and(or) cytoplasmic differences between the four base populations. There were no differences in LM, LM/BM, or LM/MBM due to possible grandmaternal and(or) cytoplasmic effects of the base populations. Ruling these out reveals important differences in maternal effects of the base populations (comparisons between reciprocal, two-way crosses) for $L M, L M / B M$, and LM/MBM. Further, the magnitude of the differences between two lines (A vs $B$ or $C$ vs $D$ ) in the pure-line vs two-way-cross data demonstrates the presence of large direct differences accompanying the maternal effect differences in $L M, L M / B M$, and $\mathrm{LM} / \mathrm{MBM}$.
Of concern when calculating heritability estimates from crossbred and(or) composite data are the possible differences in additive genetic variation between the purebred parent(s) and their crossbred offspring. Genetic parameters could be over- or underestimated because of the heterogeneity of variance, which, in turn, may affect expected response to selection in the composite population. Results from a simulation by MohdYusuff and Dickerson (1981) indicated that genetic variability in a composite population is likely to exceed that in the parental lines only under conditions of partial dominance or when the frequency of overdominant alleles falls below expected equilibrium levels. Experimental results in sheep found that heritability estimates for reproductive traits from a composite population were generally lower (or nonsignificantly higher) than heritability estimates from the parental population (Mohd-Yusuff et al., 1992). Heritability estimates for weight traits (birth, 21-d, and 42-d), average daily gain, and backfat thickness in swine were significantly different only for 21-d weight between purebred and crossbred lines (McLaren et al., 1985).

Heritability estimates for all traits, although highly variable across analyses, indicated that $\mathrm{LM}, \mathrm{BM}, \mathrm{LM} / \mathrm{BM}$, and $\mathrm{LM} / \mathrm{MBM}$ are moderately to highly heritable characteristics. Estimates pooled over all analyses were $.53 \pm .08, .54 \pm .07$, $.36 \pm .07$, and $.40 \pm .07$ for $\mathrm{LM}, \mathrm{BM}, \mathrm{LM} / \mathrm{BM}$, and LM/MBM, respectively. Previous research in laboratory and livestock species has indicated that $\mathrm{BM}$ is relative highly heritable, and that selection for increased (or decreased) BM does produce change in that trait. Estimated heritability of LM followed the same magnitude as that for $\mathrm{BM}$, with estimated heritability of LM/BM and $\mathrm{LM} / \mathrm{MBM}$ somewhat lower, indicating that direct selection for LM or its relative proportion of BM should produce changes in these characteristics. If the relationship between energy intake and relative LM, as indicated by DiCostanzo et al. (1990), holds true, then changes produced by selection for increased LM/BM, measured in mature (nongrowing), nonlactating or nongestating animals, should produce an increase in energy necessary for body maintenance, and vice versa.

Data from Burrin et al. (1988) indicate that differences in nutritional (fed vs fasted) state affect total liver metabolic activity as a result of changes in liver size and metabolic activity per unit DNA or hepatic cell. No changes were noted in metabolic activity per unit mass of the organ. This suggests that differences in energy required for maintenance may be closely linked to the mass of metabolically active tissue (for example, liver) relative to the mass of tissues that are relatively 
metabolically inactive, such as muscle and fat (Webster, 1988).

Estimates of genetic correlations, pooled across analyses, were $.87 \pm .02, .23 \pm .10$, and $.59 \pm .07$ for $B M$ with $L M, L M / B M$, and $L M / M B M$, respectively; $.75 \pm .05$ and $.96 \pm .01$ for $\mathrm{LM}$ with $\mathrm{LM} / \mathrm{BM}$ and LM/MBM, respectively; and $.88 \pm .01$ for LM/ BM with LM/MBM. Genetic correlations were large and positive for the relationship of $\mathrm{BM}$ and $\mathrm{LM}$; therefore, selection for increased mass in one of these traits would cause a proportional increase in the associated characteristic. Perhaps of more importance are the genetic correlations between $\mathrm{LM}$ and $\mathrm{LM} / \mathrm{BM}$ or LM/MBM; an increase in LM without a corresponding increase in BM for animals not growing, reproducing, or lactating would increase this ratio and, presumably, would increase maintenance energy requirement. Economically, this would probably not be desirable.

A novel approach to practicing selection to increase growth or body size while trying to reduce, or at least to avoid a concomitant increase in, energy required for maintenance would be to combine BM and LM in an index. As developed here, this would assume that metabolic activity per unit mass would be unaffected by the selection. An index of $I=B M+b L M$, where $B M$ and LM are measured in relatively mature, nonlactating animals (perhaps males retrospectively after breeding) is a possibility. Restricting this index such that the expected change in $\mathrm{BM}$ is positive, whereas that in LM is zero, means that the weighting coefficient on LM (b) is the negative value of the ratio of the genetic covariance of $L M$ and $B M$ to the genetic variance of LM. Using the data here (pooled estimates of heritabilities, phenotypic variation, etc.), such an index would be $\mathrm{I}=\mathrm{BM}-10.6 \mathrm{LM}$. Rate of response in $\mathrm{BM}$ using this index is $40 \%$ of that expected by selecting solely on BM.

\section{Implications}

Data indicate that genetic variation exists for liver mass, body mass, and liver:body mass in an outbred population of laboratory mice. Previous research indicates that a relationship between relative liver mass and maintenance energy requirement exists in mammalian species, suggesting that a proportionally larger liver mass signifies a higher maintenance energy requirement. If this is true, then a genetic basis for differences in maintenance requirements, independent of physiological state and nutritional plane, should exist. Therefore, selection to modify energy intake to satisfy maintenance requirements should produce change.

\section{Literature Cited}

Baker, R. L., A. J. Peterson, J. J. Bass, N. C. Amyes, B. H. Breier, and P. D. Gluckman. 1891. Replicated selection for insulinlike growth factor-1 and body weight in mice. Theor. Appl. Genet. 81:685.

Bünger, L., N. Remus, and D. Roschlau. 1885. Selection for different growth parameters in laboratory mice and its correlated effects on body composition and organ weights. Nahrung 28:548.

Burrin, D. G., R. A. Britton, and C. L. Ferrell. 1988. Visceral organ size and hepatocyte metabolic activity in fed and fasted rats. J. Nutr. 118:1547.

Burrin, D. G., C. L. Ferrell, R. A. Britton, and M. Bauer. 1990. Level of nutrition and visceral organ size and metabolic activity in sheep. Br. J. Nutr. 64:438.

DiCostanzo, A., J. C. Meiske, S. D. Plegge, T. M. Peters, and R. D. Goodrich. 1990. Within-herd variation in energy utilization for maintenance and gain in beef cows. J. Anim. Sci. 68:2156.

Eisen, E. J. 1986. Maturing patterns of organ weights in mice selected for rapid postweaning gain. Theor. Appl. Genet. 73: 148.

Eisen, E. J., J. F. Hayes, C. E. Allen, H. Bakker, and J. Nagai. 1978. Cellular characteristics of gonadal fat pads, livers and kidneys in two strains of mice selected for rapid growth. Growth 42:7.

Eisen, E. J., and H. Prasetyo. 1988. Estimates of genetic parameters and predicted selection responses for growth, fat and lean traits in mice. J. Anim. Sci. 66:1153.

Falconer, D. S. 1988. Introduction to Quantitative Genetics (3rd Ed.). p 168. Longman Scientific \& Technical, Harlow, Essex, U.K.

Ferrell, C. L., and T. J. Jenkins. 1884. A note on energy requirements for maintenance of lean and fat Angus, Hereford and Simmental cows. Anim. Prod. 39:305.

Ferrell, C. L., and K. J. Koong. 1986. Influence of plane of nutrition on body composition, organ size and energy utilization of Sprague-Dawley rats. J. Nutr. 116:2525.

Harvey, W. R. 1987. LSMLMW with PARMCARD. PC version (PC-1). Columbus, $\mathrm{OH}$.

Jenkins, T. J., C. L. Ferrell, and L. V. Cundiff. 1986. Relationship of components of the body among mature cows as related to size, lactation potential and possible effects on productivity. Anim. Prod. 43:245.

Koong, L. J., C. L. Ferrell, and J. A. Nienaber. 1985. Assessment of interrelationships among levels of intake and production, organ size and fasting heat production in growing animals. J. Nutr. 115:1383.

Koong, L. J., J. A. Nienaber, J. C. Pekas, and J. T. Yen. 1982. Effects of plane of nutrition on organ size and fasting heat production in pigs. J. Nutr. 112:1638.

Marshall, N. B., S. B. Andrus, and J. Mayer. 1957. Organ weights in three forms of experimental obesity in the mouse. Am. J. Physiol. 189:343.

McCarthy, J. C., and D. P. Doolittle. 1977. Effects of selection for independent changes in two highly correlated body weight traits in mice. Genet. Res. 20:133.

McLaren, D. G., D. S. Buchanan, and R. L. Hintz. 1985. Sire ranking based upon purebred versus crossbred progeny performance in swine. J. Anim. Sci. 60:802.

Mohd.Yusuff, M. K., and G. E. Dickerson. 1991. Genetic variation in composite and parental populations: Expectations for levels of dominance and gene frequency. J. Anim. Sci. 68:3983.

Mohd-Yusuff, M. K., G. E. Dickerson, and L. D. Young. 1892. Reproductive rate and genetic variation in composite and parental populations: Experimental results in sheep. J. Anim. Sci. 70:873.

Montaño-Bermudez, M., M. K. Nielsen, and G. H. Deutscher. 
1990. Energy requirements for maintenance of crossbred beef cattle with different genetic potential for milk. J. Anim. Sci. 68:2278.

Nash, D. J., and D. F. Logsdon, Jr. 1978. Morphological and physiological changes in mice (Mus musculus) selected for large size. Comp. Biochem. Physiol. A Comp. Physiol. 61: 283.

SAS. 1885. SAS User's Guide: Statistics. SAS Inst. Inc., Cary, NC.

Sharp, G. L., W. G. Hill, and A. Robertson. 1984. Effects of selection on growth, body composition and food intake in mice. I. Responses in selected traits. Genet. Res. 43:75.

Smith, N. E., and R. L. Baldwin. 1874. Effects of breed, pregnancy and lactation on weight of organs and tissues in dairy cattle. J. Dairy Sci. 57:1055.

Taylor, St. C. S., and J. I. Murray. 1891. Effect of feeding level, breed and milking potential on body tissues and organs of mature, non-lactating cows. Anim. Prod. 53:27.

Webster, A.J.F. 1981. The energetic efficiency of metabolism. Proc. Nutr. Soc. 40:121.

Webster, A.J.F. 1989. Bioenergetics, bioengineering and growth. Anim. Prod. 48:248. 